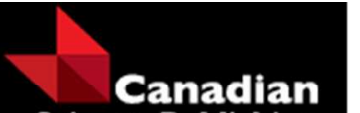

Science Publishing

Canadian Journal of Forest Research Revue canadienne de recherche forestière

\title{
Variation in Fire Scar Phenology from Mixed Conifer Trees in the Sierra Nevada
}

\begin{tabular}{|r|l|}
\hline Journal: & Canadian Journal of Forest Research \\
\hline Manuscript ID & cjfr-2017-0297.R1 \\
\hline Date Submitted by the Author: & 23-Oct-2017 \\
\hline Complete List of Authors: & $\begin{array}{l}\text { Stephens, Scott; University of California, Berkeley } \\
\text { Maier, Liam; University of California Berkeley, ESPM } \\
\text { Gonen, Lilah; University of California Berkeley, } \\
\text { York, Jennifer; University of California Berkeley } \\
\text { Collins, Brandon; University of California Berkeley, } \\
\text { Fry, Danny; University of California Berkeley, ; }\end{array}$ \\
\hline Keyword: & $\begin{array}{l}\text { cambium phenology, dendrochronology, fire regime, fire scar, fire } \\
\text { seasonality }\end{array}$ \\
\hline $\begin{array}{r}\text { Is the invited manuscript for } \\
\text { consideration in a Special } \\
\text { Issue? : }\end{array}$ & N/A \\
\hline \multicolumn{2}{|c}{} \\
\hline
\end{tabular}

SCHOLARONE $^{\text {Im }}$

Manuscripts 
5 Scott L. Stephens ${ }^{1}$, Liam Maier $^{1}$, Lilah Gonen ${ }^{1}$, Jennifer D. York ${ }^{2}$, Brandon M. Collins ${ }^{3}$, and Danny L. Fry ${ }^{1}$

$9{ }^{1}$ Department of Environmental Science, Policy, and Management, 130 Mulford Hall, University of California, Berkeley, CA 94720-3114 USA

$12{ }^{3}$ Center for Fire Research and Outreach, University of California, Berkeley, CA 94720-3114 
24 Abstract

25 Fire-scar-based studies have provided robust reconstructions of past fire regimes. The season in

26 which a fire occurs can have considerable impacts to ecosystems but inference on seasonality

27 from fire scars is relatively uncertain. This study examined patterns in the phenology of

28 cambium formation and wounding responses in the five common mixed conifer tree species of

29 the Sierra Nevada. The outer bark was shaved on 35 trees and individual locations within the

30 shaved portions were wounded systematically by applying direct heat using a handheld torch.

31 Most of the trees had not commenced annual ring development by the first burning treatment in

32 late May. By the second treatment scars were identified mostly within the early or middle

33 earlywood, although variation was high compared to other treatment periods. By late October, all

34 scars were recorded at the ring boundary. Although intra-ring scar positions generally followed a

35 logical temporal pattern, there was high tree-to-tree variation such as Douglas-fir burned on 26

36 June induced scars in the early-, mid-, and late-earlywood depending on the individual tree. This

37 high variation makes it somewhat challenging to precisely assign past fire season to published

38 fire history studies.

40 Keywords: cambium phenology, dendrochronology, fire regime, fire scar, fire seasonality

42 Introduction

43 Using dendrochronological techniques, tree-ring fire scars are dated with annual

44 resolution, and with multiple fire-scarred samples collected across a given area, fire regime

45 attributes such as frequency and spatial extent can be estimated (Farris et al. 2010; Krasnow et al.

46 2016). The network of fire-scar-based studies in conifer forests across western North America 
47 has provided robust reconstructions of past fire regimes and insights on multi-scale patterns of

48 fire synchronicity and fire-climate relationships (Kitzberger et al. 2007; Falk et al. 2011).

The intra-annual position of the scar should allow for a more precise assignment of the

50 seasonal timing of fire occurrence. Scar position is usually assigned to being in the earlywood,

51 latewood, or the dormant period between annual rings. Extending the observed intra-annual

52 position of the scar to the assignment of calendrical season requires greater understanding of the

53 timing of wood production and differentiation. The seasonal timing of cambial growth varies by

54 several factors including the differential response of species to the environmental parameters that

55 control their growth (Fritts 1976; Schmidt and Lotan 1980).

The season in which a fire occurs can have considerable impacts on ecosystem structure

57 and function, independent of fire intensity. Knapp et al. (2009) conducted a comprehensive

58 review which identified ecologically relevant differences in fire effects between early and late

59 season prescribed fires. These differences included not only a range of impacts to flora and

60 fauna, but also in fuel consumption. Given contemporary record keeping practices calendar dates

61 for prescribed fires are mostly known; the same is not necessarily true for historical fires

62 identified within tree rings. This study seeks to identify patterns in the phenology of cambium

63 formation and wounding response in the five common mixed conifer species of the Sierra

64 Nevada. The specific objectives were: 1) identify the intra-ring location of thermally induced

65 scars applied to tree boles, and 2) assess individual species responses to different timing of

66 thermal injuries.

67

68 Methods

69 Study Area 
The study was conducted at the University of California Blodgett Forest Research Station

71 (BFRS; 38 $540^{\prime} \mathrm{N}, 120^{\circ} 390^{\prime} \mathrm{W}$ ); an experimental research forest on the western slopes of the

72 northern Sierra Nevada, approximately $21 \mathrm{~km}$ east of Georgetown, California. BFRS (1174 ha) is

73 a mixed-conifer forest with an overstory composed of sugar pine (Pinus lambertiana), ponderosa

74 pine (P. ponderosa), white fir (Abies concolor), incense-cedar (Calocedrus decurrens), Douglas-

75 fir (Pseudotsuga menziesii), and California black oak (Quercus kelloggii). Elevation ranges from

761100 to $1410 \mathrm{~m}$ and total annual precipitation averages $1600 \mathrm{~mm}$, falling mainly between

77 September and May. The average minimum daily temperature in January is $0.6^{\circ} \mathrm{C}$ and the

78 average maximum daily temperature in July is $28.3^{\circ} \mathrm{C}$. Wildfires are suppressed at BFRS; prior

79 to the policy of fire suppression which began early in the $20^{\text {th }}$ century, the median composite fire

80 interval at the 9-15 ha spatial scale was 4.7 years with a range of 4-28 years (Stephens and

81 Collins 2004).

82 Treatment

83 Three healthy overstory trees from of each of the five conifer species were selected from

84 two separate management units (plots) for this study. In one plot, one tree from each species was

85 selected to serve as a control ( $n=35$ trees total). Age at base height and diameter at breast height

$86(\mathrm{DBH})$ were collected for each tree. Thirty trees received six identical burn treatments

87 administered over a six-month period which extended from May to October in 2010. Every

88 control and treatment tree had all but a thin layer of bark removed (approximately $2.5 \mathrm{~cm}$ of bark

89 remained after shaving) from its main stem using a hatchet, approximately $30 \mathrm{~cm}$ by $90 \mathrm{~cm}$ along

90 the circumference of the bole, and approximately $25 \mathrm{~cm}$ above the forest floor (Figure 1). This

91 was done in an effort to reduce intra- and inter-tree variations in bark thickness that may have

92 induced differential responses to identical treatments. We realize that the thermal bark properties 
93 for each species vary, which could influence the degree of cambial injury from heating. That

94 said, Martin (1963) reported little variation in thermal diffusivity over wide ranges of bark

95 density, moisture content, and temperature. The six within-tree bark burn treatments were

96 positioned approximately $15-30 \mathrm{~cm}$ apart and horizontally arranged along one side of each tree's

97 stem (Figure 1).

98 Bark-stripped sites were wounded systematically, at roughly one-month intervals, by

99 applying direct heat to tree bark surfaces using a handheld propane torch for approximately 15

100 minutes; fifteen minutes was estimated to be sufficient based on Peterson and Ryan (1986,

101 equation 10) which derived the relationship between bark thickness and the amount of time

102 needed to kill the cambium given a fire with a constant temperature. The upper edge of the area

103 of shaved bark was marked with an aluminum nail driven into the stem and which remained in

104 place through the course of the study (Figure 1). Control trees were shaved but received no heat

105 treatment.

106 After all treatments had been applied, trees continued to grow for three years before

107 being hand-felled in 2014. Half-rounds, containing the six temporally (and spatially) separated

108 treatments, were then taken from each tree. Sample extractions were completed using, first, a

109 chainsaw to cut out the centers out of the half-rounds and segment the remaining scar-containing

110 round into smaller pieces, most of which contained 1-2 treatment loci. Multiple horizontal cross-

111 sections were then taken from each scar by passing the samples through a bandsaw. To prepare

112 scar cross sections for analysis, samples were sanded until the cellular structure was visible

113 (Figure 1). The within-annual-ring position of each scar was evaluated by three independent

114 viewers using a dissecting microscope and recorded as EE (early earlywood), ME (middle

115 earlywood), LE (late earlywood), L (latewood), and RB (ring boundary, identified as pre- or 
116 post-growth of the annual ring). The multiple observers were trained together to increase

117 consistency and some scars were sent to a senior dendrochronologist (Dr. Peter Brown) to verify

118 recorded scar positions.

119 To describe the climate preceding the treatment application, we summarized temperature 120 and precipitation collected from the Bald Mountain Remote Automated Weather Station (38 $54^{\prime}$

$121 \mathrm{~N}, 120^{\circ} 42^{\prime} \mathrm{W}$; $1427 \mathrm{~m}$ elevation), 3-5 km from the BFRS study areas. We used analysis of

122 variance to determine if significant differences $(\mathrm{p}<0.05)$ existed in tree age and tree size

123 between plots and species. If a significant difference was detected, pairwise multiple

124 comparisons using the Tukey-Kramer HSD test identified which species were statistically 125 different.

126

$127 \quad$ Results

128 For the six months preceding the treatment, the monthly mean of the daily maximum 129 temperature approximated the long-term average (data not shown). Only in December was the 130 mean temperature less than $90 \%$ of the long-term mean. Total precipitation from October 2009 131 through March 2010 was $94.7 \mathrm{~cm}$, compared to the long-term mean of $99 \mathrm{~cm}$. Monthly 132 precipitation totals in the 2009-2010 wet season were higher in four of the six months and $11 \%$ 133 higher in February and March compared to the long-term means. The mixed conifer tree species that was most difficult to remove the bark from was

135 Douglas-fir. It took approximately twice as long to shave this species with a hatchet as compared 136 to the other mixed conifer species. Ponderosa pines had relatively thick bark under their plates 137 but bark thickness beneath their bark furrows was much thinner. When Douglas-fir was treated 138 with the handheld propane torch its bark expanded outward by several centimeters during 
139 combustion, no other species did this when the torch was applied. Small segments of burning

140 sugar pine bark (approximately 1-2 $\mathrm{cm}$ in diameter) were ejected up to $50 \mathrm{~cm}$ away from the tree 141 when burned by the torch.

142 The mean DBH for all trees was $69.4 \mathrm{~cm}(\mathrm{SE}=3.2 \mathrm{~cm})$ and individual tree sizes ranged 143 from $40.2 \mathrm{~cm}$ to $78 \mathrm{~cm}$ (Table 1). There was no difference in tree sizes between plots $(\mathrm{t}$-test=$144 \quad 0.824 ; \mathrm{p}=0.414)$. Across species there were significant differences in tree sizes $(\mathrm{F}$ value $=8.232$; $145 \mathrm{p}$-value $=0.000)$. Mean DBH for incense-cedar was significantly lower than Douglas-fir $146(p=0.047)$, ponderosa pine $(p=0.019)$, and sugar pine $(p=0.000)$. White fir had significantly 147 smaller DBH than sugar pine $(\mathrm{p}=0.012)$. The mean age of the trees was 93.6 years $(\mathrm{SE}=1.9$ 148 years) and individual ages ranged from 78 to 128 years. Most tree ages ranged from 80 to 90 149 years except for two incense-cedars (125 and 128 years old), which persisted through timber 150 harvesting that took place in the early $20^{\text {th }}$ century (Stephens and Collins 2004). There was no 151 difference in tree age between plots $(\mathrm{t}$-test $=1.290 ; \mathrm{p}=0.118)$ or species $(\mathrm{F}$-value $=1.30 ; \mathrm{p}=$ $1520.293)$.

There was no observable impact of bark shaving on tree-ring development in the control 154 trees. The proportion of trees that formed visible fire scars across the six treatment applications 155 was relatively low despite having bark shaved down to approximately $2.5 \mathrm{~cm}$ thick (see 156 Supplementary Materials). Douglas-fir and white fir had the lowest incidence of scar formation. 157 Most of the trees (88\%) had not commenced annual ring development by the first treatment on 158 May $20^{\text {th }}$ (Table 2). By the second treatment most of the scars were identified within the early $159(30 \%)$ or middle earlywood (56\%) portion of the annual ring (Figure 2$)$. Incense-cedar had the 160 largest range in scar location (EE to L), whereas all of the white firs were in the ME. In the third 161 and fourth treatment applications the observed scar location was focused in the LE (76\%) and L 
$162(91 \%)$, respectively. Half the recording trees stopped ring development by September $30^{\text {th }}$,

163 including all of the incense-cedars. With the exception of two ponderosa pine trees and one sugar

164 pine all scars resulting from September $7^{\text {th }}$ or later were in the L or RB. By the last burning

165 treatment date (October $29^{\text {th }}$ ), all of the scars were recorded at the RB.

166 Although intra-ring scar positions generally followed a logical temporal pattern (Table 2)

167 there was high tree-to-tree variation in the stage of annual xylem increment formation (Table

$168 \mathrm{~S} 1)$. As an example of this variation Douglas-fir burned on June $26^{\text {th }}$ resulted in visible scar

169 formation in the early-, mid-, and late-earlywood, while incense-cedar burned on July $26^{\text {th }}$

170 resulted in visible scar formation in middle- and late-earlywood and in latewood depending on

171 the individual tree (Figure 2).

172

173 Discussion

174 Despite our efforts to meticulously shave bark from the treatment area, few trees possessed a

175 complete series of burn scars. Non-scarred samples were common and often displayed a great

176 deal of bark scorch, but no sign of vascular damage or healed wounds (Figure 1). Tree bark

177 provides critical protection from radiant and convective heat and our study demonstrated that

178 even bark thicknesses of $2.5 \mathrm{~cm}$ could retard injury.

179 California mixed conifer forest species exhibit a variety of bark structures. Incense-cedar 180 has a dense fibrous wooden sheath, while ponderosa pine has thick bark that falls away from 181 their stems in jigsaw-puzzle shaped pieces. White fir has a corky bark which tends to be thinner 182 than that of Douglas-fir but similar in density (van Mantgem and Schwartz 2003); both of these 183 species had the lowest proportion of scar formation likely due to their higher heat tolerances, at 184 least for Douglas-fir (Peterson and Ryan 1986; van Mantgem and Schwartz 2003). Intra-species 
185 variation in bark properties can often be attributed to differences in age, plot history, and/or 186 genetic potentials (cited in Ryan and Reinhardt (1988)).

Heyerdahl et al. (2007) found variation in fire scar position among species and

188 topographic position in ponderosa pine and mixed conifer forests in British Columbia, Canada.

189 The majority of scars on Douglas-fir trees were located on the ring boundary regardless of

190 aspect. Ponderosa pine fire scars tended to occur within the annual ring (i.e., growing season) on

191 north aspects, and within the annual ring and at the ring boundary on south aspects.

192 The percentage of Douglas-fir trees that received fire scars from the hand held torch was

193 the lowest of all species (Table S1). Our observation of how Douglas-fir bark expanded during

194 burning could have contributed to this by providing additional cambium insulation to retard

195 injury and others have found high stem heat tolerance of this species (Peterson and Ryan 1986).

196 Other mixed conifer tree species also had relatively low amounts of scarring in this study

197 (Supplementary Materials), possibly shaving the bark even more before the torch was applied

198 could have enhance scarring. Even with our study limitations the sequence of fire scar locations

199 from Blodgett Forest revealed a logical temporal pattern that began at the dormant position,

200 followed by different percentages of earlywood and latewood scars, and ending with the dormant

201 position at the end of the season (Table 2). This pattern generally supports the continued use of

202 intra-ring scar positions to capture distinct periods within a given growing season. However,

203 high tree-to-tree variation within individual species in annual xylem increment formation,

204 especially early in the growing season, makes it somewhat challenging to precisely assign past

205 fire season to published fire history studies.

206 Acknowledgements 
207 We wish to thank Rob York, Jana Nisbet, Zev Balsen, and Blodgett Forest staff for logistical

208 support in applying the treatments and transport of samples; we also thank the loggers that

209 harvested the trees while preserving our fire scars. We appreciate Peter Brown's assistance in 210 interpreting our fire scarred samples. 
211 References

212 Falk, D.A., Heyerdahl, E.K, Brown, P.M, Farris, C., Fulé, P.Z., McKenzie, D., Swetnam, T.W.,

213 Taylor, A.H., and Van Horne, M.L. 2011. Multiscale controls of historical forest-fire

214 regimes: new insights from fire-scar networks. Frontiers Ecol. Envir. 9: 446-454.

215 Farris, C.A., Baisan, C.H., Falk, D.A., Yool, S.R., and Swetnam, T.W. 2010. Spatial and

216 temporal corroboration of a fire-scar-based fire history in a frequently burned ponderosa pine

217 forest. Ecol. Apps. 20: 1598-1614. DOI: 10.1890/09-1535.1.

218 Fritts, H.C. 1976. Tree Rings and Climate. Academic Press, New York.

219 Heyerdahl, E.K., Lertzman, K., and Karpuk, S. 2007. Local-scale controls of a low-severity fire

220 regime (17500-1950), southern British Columbia, Canada. Ecoscience 14: 40-47.

221 Knapp, E.E., Estes, B.L., and Skinner, C.N. 2009. Ecological effects of prescribed fire season: a

222 literature review and synthesis for managers. USDA Forest Service, Pacific Southwest

223 Research Station, GTR-224, Albany, CA.

224 Krasnow, K.D., Fry, D.L., and Stephens, S.L. 2016. Spatial, temporal and latitudinal components

225 of historical fire regimes in mixed conifer forests, California. J. Biogeography 1-15,

226 doi:10.1111/jbi.12914

227 Kitzberger, T., Brown, P.M., Heyerdahl, E.K., Swetnam, T.W., and Veblen, T.T. 2007.

228 Contingent Pacific-Atlantic Ocean influence on multicentury wildfire synchrony over

229 western North America. Proc. Natl. Acad. Sci. USA 104: 543-548.

230 Martin, R.E., 1963. Thermal properties of bark. For. Prod. J. 8: 419-426.

231 Peterson, D.L., and Ryan, K.C. 1986. Modeling post-fire conifer mortality for long-range

232 planning. Environ. Manage. 10: 797-808. 
233 Ryan, K.C. and Reinhardt, E.D. 1988. Predicting postfire mortality of seven western conifers.

234 Can. J. For. Res. 18: 1291-1297.

235 Schmidt, W.C., and Lotan, J.E. 1980. Phenology of common forest flora of the northern Rockies-

$236-1928$ to 1937. USDA Forest Service, Intermountain Forest and Range Experiment Station.

237 Research Paper INT-259. Ogden, UT.

238 Stephens, S.L. and Collins, B.M. 2004. Fire regimes of mixed conifer forests in the north-central

239 Sierra Nevada at multiple spatial scales. Northwest Sci. 78: 12-23.

240 van Mantgem, P., and Schwartz, M. 2003. Bark heat resistance of small trees in Californian

241 mixed conifer forests: testing some model assumptions. For. Ecol. Manage. 178: 341-352.

242 
243 Table 1. Average (one standard error) diameter at breast height (DBH) and age of trees (at stump

244 height; $\mathrm{n}=7$ for each species) used in the fire scar study.

\begin{tabular}{lcc}
\hline Species & DBH (cm) & Age (yrs) \\
\hline Douglas-fir & $70.4(5.2)$ & $93.3(2.6)$ \\
Incense-cedar & $48.7(2.6)$ & $101.3(7.1)$ \\
Ponderosa pine & $73.3(4.1)$ & $93.6(3.9)$ \\
Sugar pine & $90.4(8.7)$ & $89.6(3.1)$ \\
White fir & $64.3(3.9)$ & $90.0(1.6)$ \\
\hline
\end{tabular}

245

246

247

248

249 
250 Table 2. Summary of intra-ring scar position and calendar date for fire injuries applied to mixed

251 conifer trees at UC Blodgett Forest in 2010. Values are percent of samples scarred with intra-ring

252 location determined as early earlywood (EE), middle earlywood (ME), late earlywood (LE),

253 latewood (L), and ring boundary $(\mathrm{RB})$.

\begin{tabular}{llllll}
\hline Date & EE & ME & LE & L & RB
\end{tabular}

\begin{tabular}{llll}
\hline May 20 & 6 & 6 & 88
\end{tabular}

$\begin{array}{lllll}\text { June } 26 & 30 & 57 & 9 & 4\end{array}$

July $26 \quad 14 \quad 76 \quad 10$

$\begin{array}{ll}\text { Sept. } 7 & 9\end{array}$

$\begin{array}{llll}\text { Sept. } 30 & 5 & 45 & 50\end{array}$

$\begin{array}{ll}\text { Oct. } 29 & 100\end{array}$ 
266 Figure 1. Photos show tree samples at different stages of the study: treatment application via

267 handheld blowtorch on the bole of a sugar pine where the bark was shaved (A); bole of a white

268 fir showing the five treatment applications, with a nail marking each location (B); partial cross

269 section of a white fir with an early earlywood scar (C); ponderosa pine with a late earlywood

270 scar (D).

271
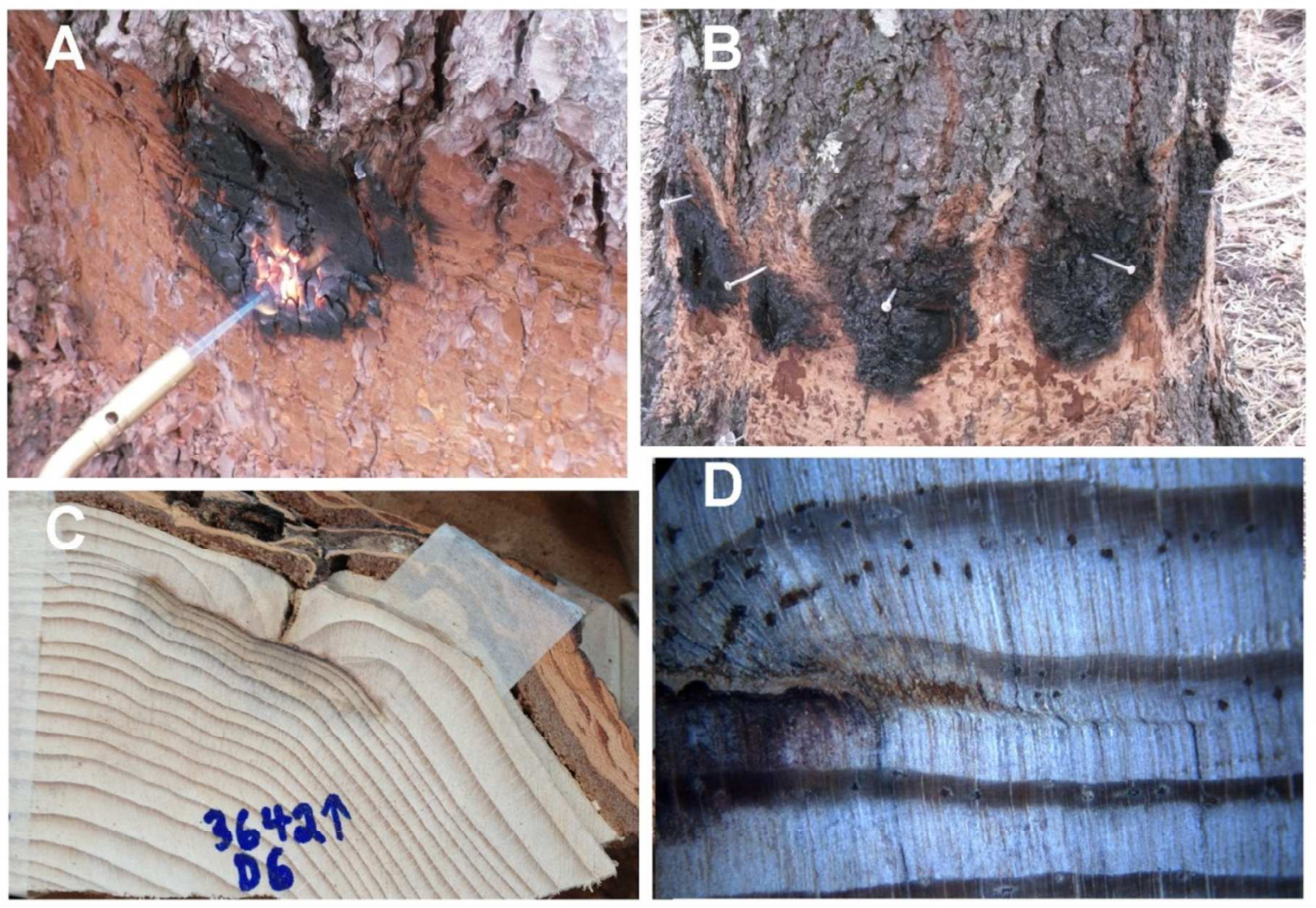
276 Figure 2. Percent of observed trees (within species and date) with an intra-annual position or ring

277 boundary fire scar in treated trees at Blodgett Forest Research Station, Georgetown, California.

278 Positions included early earlywood (EE), middle earlywood (ME), late earlywood (LE),

279 latewood (L), or ring boundary (RB). Tree species included Douglas-fir (DF), incense-cedar

280 (IC), ponderosa pine (PP), sugar pine (SP), and white fir (WF).

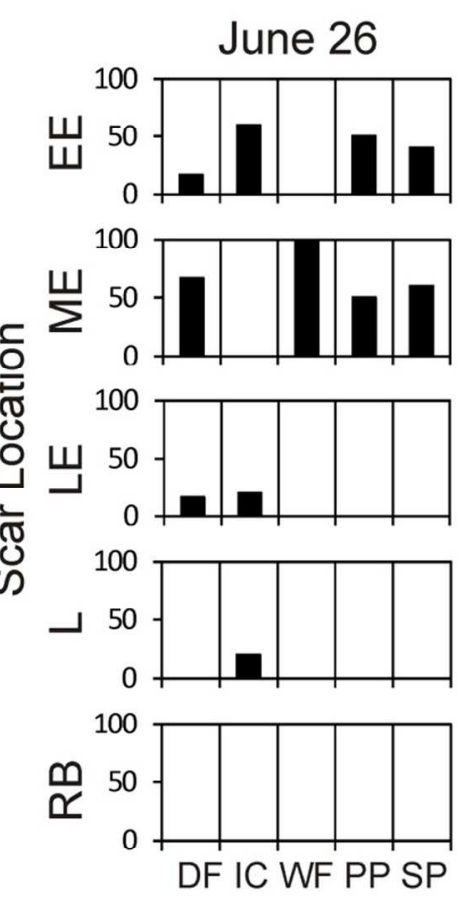

281

282

283

284
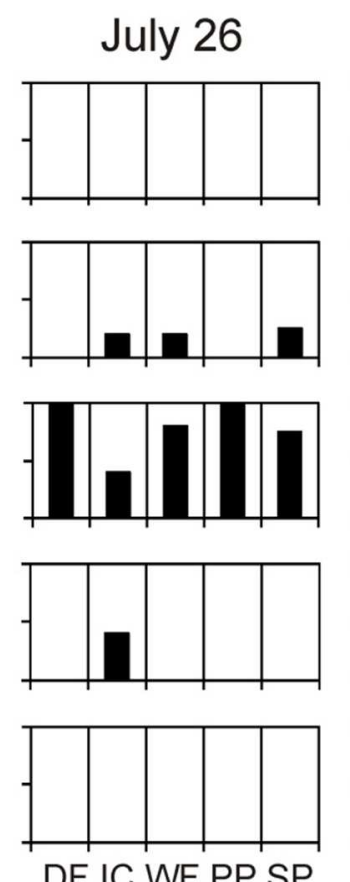

\section{Species}

Sept 7
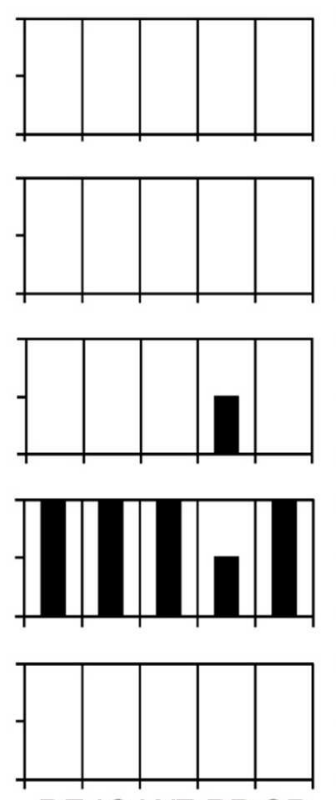

DF IC WF PP SP

\section{Sept 30}
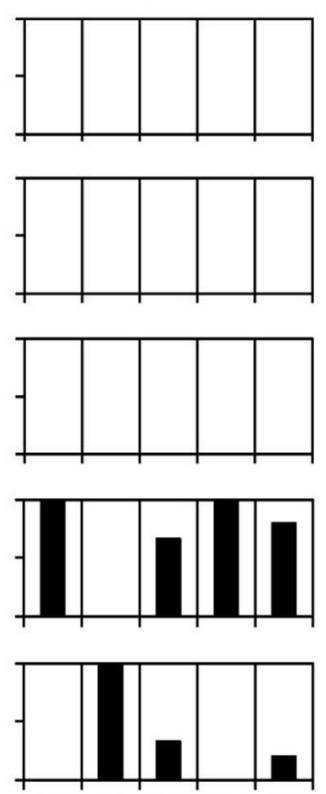

DF IC WF PP SP 
1 Supplementary Materials

2 Table S1. Number of observed trees with an intra-ring or ring boundary fire scar position

3 identified at each of the six application dates during the growing season. Sept, September; Oct,

4 October; DF, Douglas-fir; IC, incense-cedar; PP, ponderosa pine; SP, sugar pine; WF, white fir.

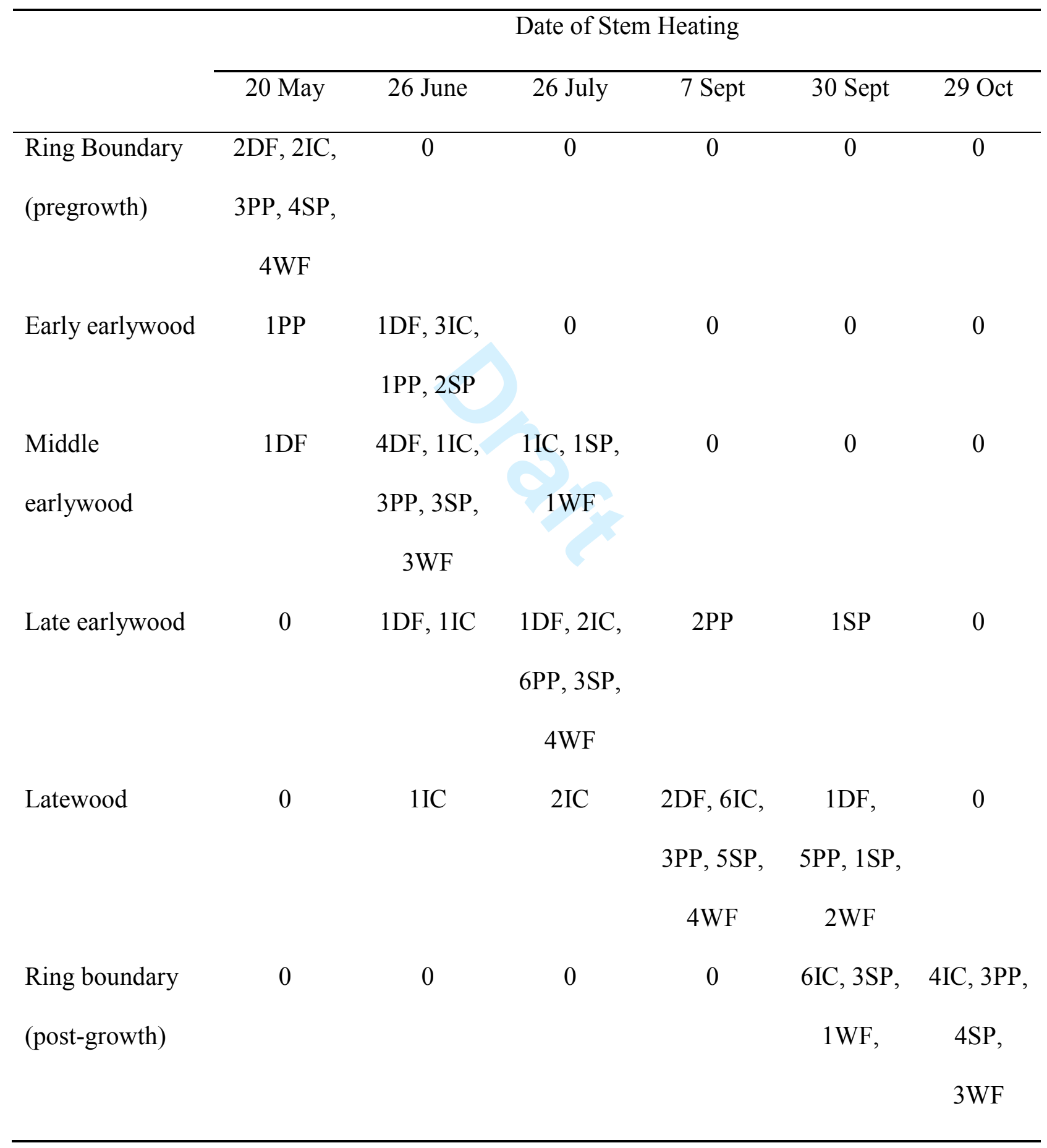


